\title{
The Influence of Grinding Parameters of Talc on Water- Based Paint Properties: Application of Multivariate Regression Analysis
}

\author{
Murat Muduroglu', Muhammed Fatih Can ${ }^{1}$ (D) Baris Ergul ${ }^{2}$ (D) \\ ${ }^{1}$ Afyon Kocatepe University, Department of Mining Engineering, Afyon, Turkey \\ ${ }^{2}$ Eskisehir Osmangazi University, Department of Statistics, Eskisehir, Turkey
}

\section{A B S T R ACT}

mil $\mathrm{n}$ this study, the influence of grinding parameters of talc sample in the conventional ball mill on water-based paint properties was investigated, and the results obtained from the experiments were statistically modeled. The regression analysis were designed to reveal the correlation between grinding parameters of the talc and the opacity and brightness of the paint with the recipes containing prepared mineral. In multivariate regression analysis, the differential grinding parameters were used to determine the change on opacity and brightness of the paint with a linear model between the change of the grinding parameters as the variables. Therefore, developed analysis includes a numerical model which could foresee the changes on final paint properties due to parameter changes (ball charge, material charge and time) in the grinding process. At the end of the experimental studies, the results indicated that the changes on brightness and opacity of a water-based paint are very dependant to the characteristics of talc mineral used as a filler in the same recipe. In other words, it was possible to foresee the changes on opacity and brightness of the paint due to changing grinding parameters of talc used as mineral filler in paint by using multivariate multiple regression analysis.

Keywords:

Talc, Grinding, Grinding parameters, Paint, Opacity (OP), Brightness (BR), Multivariate regression analysis (MRA), Modeling.

\section{INTRODUCTION}

Coat oating applied for coloring material or protection purpose is called as paint. Besides their coloring feature paints have also hidden and protective properties. Colorless binder and solvent composition specially applied on wooden materials are called lacquer (Yurekli, 1997, Paksoy, 1999).

There are many raw materials used in paint production. These raw materials can be classified under 4 main groups as; binders, solvents, pigments/mineral fillers, and additives. Industrial minerals/mineral fillers have a significant role in paint production and can be used up to $50 \%$ in a typical water-based paint formula. Mineral fillers are widely used in paper, coating, and paint industries in order to enhance the properties of the final product by decreasing the production costs. In the paint industry the pigments are utilized with fillers, and both are in very fine size and required to be extensively dispersed in the paint. The mineral ingredients have active roles in the paint layer formation, strength, durability, OP, and color of the final coating (Conceição et al., 2018). Several minerals and the chemical process should be applied to industrial minerals before their use in paint recipes. $\mathrm{TiO}_{2}$, calcium carbonate (natural \& precipitated), zinc oxide, kaolinite (natural \& calcined), talc, mica, quartz, dolomite, and barite are main raw materials used in the paint (Ciullo, 1996). Moreover, the mineral fillers are known to provide some unique coating characteristics, in terms of, providing OP, the balance of BR, better surface finish and ease at application (Conceição et al., 2018). Additionally, they help to reduce production/recipe cost. Despite being at the sixth row in paint production in Europe, Turkey imports most of the fillers and additives (Karakas, 2011).

Talc is ahydro magnesium silicate, $\mathrm{Mg}_{3}\left(\mathrm{Si}_{2} \mathrm{O}_{5}\right)_{2}(\mathrm{OH})_{2}$ and commonly used as a mineral filler in the paint industry (State Planning Organization, SPO, 2001). Ideally, it consists of $31.7 \% \mathrm{MgO}, 63.5 \% \mathrm{SiO}_{2}$, and $4.8 \%$ water (Grim, 1968). Talc can reduce the settling ratio of pigment together with the positive effect on OP in the paint. Blistering and cleavages in a paint can also be elimina- 
ted by using talk. It inhibits moisture transfer to the material, and increases the corrosion resistance of the paint due to a platy form of talc. Talc is also used in primer coatings due to better adherence property compared to other fillers. However, it is not recommended to use talc over a certain amount in a recipe because of its high dusting characteristics (Gündüz, 2005).

The performance of talc in painting depends on its physical characteristics such as particle morphology, particle size distribution, and oil absorption (Yekeler et al., 2004). These characteristics directly affect the interactions between mineral particles and other raw materials in paint, and hence the properties of the paint are changed. Talc is crushed and ground to obtain proper micron size before used in paint recipes. Grinding is generally performed in ball mills. Paint producers' demand for the homogeneous product (Conceiçãoet al., 2018). Within water based coatings, talc has a satisfying performance with sustainable raw material quality. However, this quality may vary as the talc suppliers utilize different set ups for liberating/comminution processes. This leads talc products with different characteristics to be obtained upon different grinding parameters and the use of these different talc products in the paint may deteriorate the permanence of paint quality in industrial production line.

Generally, regression analysis and response surface methods are applied in literature. The basic principle of the response surface is a polynomial relationship between control and response variables (Bezerra et al., 2008). In some advanced cases, models at second-order fit better and cubic terms can be used for complex cases. The response surface data have been digitized with a regression model to form a response surface (Box and Hunter, 1961; Bezerra et al., 2008). Moreover, Bootstrap, Bayesian and Ordinary Least Squares are also valid methods to estimate the parameters of the model methods (Wold, 1973; Wold, et al., 2001).

In this context, the aim of this study was to investigate the correlation between grinding parameters of the talc and the physical properties (OP and BR) of the paint with the recipes containing prepared mineral.

The results obtained from the grinding experiments were also statistically modeled. The regression analysis was designed to reveal the correlation between the grinding parameters of the talc and the final properties of the paint. In MRA, the differential grinding parameters were used to determine the change on OP and BR of the paint with a linear model between the change of the grinding parameters as the variables.

\section{MATERIAL AND METHODS Material}

The raw sample of talc used in this study was supplied from the Sivas region of Turkey.

The chemical analysis of the sample was done by using Bruker S8 Tiger model X-ray floresans (XRF) spectrophotometer. First, the sample was ground under $100 \mu \mathrm{m}$, and then, $1.5 \mathrm{~g}$ of the sample was mixed with $7.5 \mathrm{~g}$ of $\mathrm{LiBO}_{4}+\mathrm{LiB}_{4} \mathrm{O}_{7}$ mix. Before the measurement, the mixture was transformed to glass pellet form by fusion method. The result of the chemical analysis of the sample is presented in Table 1. Additionally, the mineralogical analysis of the sample was done using a Rigaku ZSX Primus II model x-ray diffraction (XRD) with using $\mathrm{CuK} \alpha$ radiation, and the XRD result of the sample is seen in Fig. 1. As seen from Fig. 1, the major mineral was the talc in the sample. This result indicated that the sample was pure enough for the experiments.

Table 1. Chemical Analysis (XRF) of raw talc sample
$\begin{array}{cccccccccc}\text { Comp. } & \mathrm{SiO}_{2} & \mathrm{MgO} & \mathrm{Fe}_{2} \mathrm{O}_{3} & \mathrm{Al}_{2} \mathrm{O}_{3} & \mathrm{CaO} & \mathrm{Na}_{2} \mathrm{O} & \mathrm{CuO} & \mathrm{K}_{2} \mathrm{O} & \text { LOI } \\ \text { (\%) } & 63.4 & 33.7 & 0.47 & 0.05 & 0.05 & 0,02 & 0.01 & \begin{array}{c}90 \\ (\mathrm{ppm})\end{array} & 2.3\end{array}$

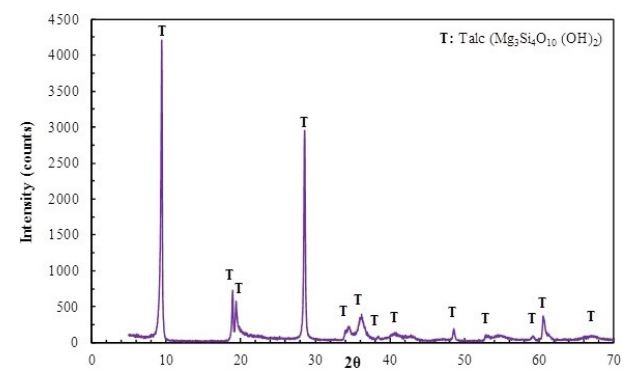

Figure 1. XRD graph of the raw talc sample

\section{Grinding of talc}

The laboratory type ceramic ball mill by using alumina balls were utilized for laboratory scale talc sample grinding. Before the grinding process, the particle size of raw talc sample was decreased to $-1 \mathrm{~mm}$ by an impact crusher. In the grinding experiments; the ball size and distribution, ball feed(j), material feed( $\left.\mathrm{f}_{\mathrm{c}}\right)$, critical speed $\left(\% \mathrm{~N}_{\mathrm{c}}\right)$, and time of grinding were optimized. The conditions for the mill, media, and material used in the grinding experiments are presented in Table 2.

\section{Preparation of paint}

The solid/liquid suspensions for water based paint were prepared in a $1.000 \mathrm{ml}$ volume lab container, considering the complete components in paint recipe. The paints were prepared by using a laboratory type high speed (20.000 rpm max.) disperser/dissolver. In current research, white pigment containing paint ingredient was determined, including the following percentages of the formulation: Pigment $=53 \%\left(15 \% \mathrm{TiO}_{2}\right.$ and $38 \%$ filler $)$, re- 
Table 2. Properties of mill, media, and material used in grinding experiments.

\begin{tabular}{|c|c|c|}
\hline \multirow{4}{*}{$\begin{array}{c}\text { Mill } \\
\text { (Ceramic) }\end{array}$} & Volume $\left(\mathrm{cm}^{3}\right)$ & 3.000 \\
\hline & Dimensions & $\begin{array}{l}\text { Diameter: } 150 \mathrm{~mm} \\
\text { Length: } 200 \mathrm{~mm}\end{array}$ \\
\hline & Critical speed (\%Nc) & $50,60,70,75,80,85,90$ \\
\hline & Grinding time ( $\mathrm{min}$ ) & $30,45,60,90,120$ \\
\hline \multirow{4}{*}{$\begin{array}{c}\text { Media } \\
\text { (Alumina } \\
\text { balls) }\end{array}$} & Ball sizes (mm ) & $12,16,20$ \\
\hline & Ball density $\left(\mathrm{g} / \mathrm{cm}^{3}\right)$ & 2,80 \\
\hline & Ball feed (\%) (j) & $0.25 ; 0.30 ; 0.35 ; 0.40 ; 0.45$ \\
\hline & $\begin{array}{l}\text { Ball size distribution } \\
(12,16,20 \mathrm{~mm}) \% w t .\end{array}$ & $50-25-25$ \\
\hline \multirow{3}{*}{$\begin{array}{c}\text { Material } \\
\text { (Talc } \\
\text { sample ) }\end{array}$} & Density $\left(\mathrm{g} / \mathrm{cm}^{3}\right)$ & 2,9 \\
\hline & Bulk density $\left(\mathrm{g} / \mathrm{cm}^{3}\right)$ & 0.957 \\
\hline & $\begin{array}{l}\text { Material feed (\%) } \\
\text { (fc ) }\end{array}$ & $0.120 ; 0.140 ; 0.160 ; 0.190 ; 0.210$ \\
\hline
\end{tabular}

$\sin =18 \%$, additives $=2.5 \%$ (defoamer, dispersant, bactericide, biocide, thickener, surfactant, and coalescent), and solvent $=26.5 \%$ water. Throughout the investigations, the ingredients ratios (pigments/mineral filler, resin, solvent, and additives) were kept constant. Only the type of talc sample used as a functional filler in the recipe was changed. Leneta type cardboards were used for OP and BR measurements. Gloss, viscosity, pH were also measured. The major properties of a coating which are related to the filler quality, are the OP and BR. Therefore, these properties were used in regression analysis. The OP has no unit, and is calculated from Equation (1) (Conceiçãoet. al.,2018):

$$
O P(\%)=\frac{R_{p}}{R_{b}} \cdot 100
$$

Here:

$\mathrm{R}_{\mathrm{p}}=$ reflectance under the black background .

$R_{b}=$ reflectance under the white background

Datacolor spectrophotometer was used to define the OP of the paint dry film. As a general application the paint was spread on white cardboard with a black strip, type Leneta, using a $100 \mu \mathrm{m}$ thick extender. Hiding power/opacity was calculated according to TS ISO 6504-3 standard.

The brightness/gloss values were defined by Sheen gloss meter on the dry film. This time the paint was spread on a glass surface, with a extender of $100 \mu \mathrm{m}$ thickness. Brightness/gloss was calculated according to TS ISO 6504-3 standard as well.

The chosen functional filler was different talc samples obtained under different grinding conditions.

\section{Multivariate Linear Regression Analysis (MRA)}

Whenever a mathematical model required to explain the relationship between two or more variables with a causal relationship, the regression analysis which is a statistical analysis technique is chosen.

The simple linear regression model includes a dependent and independent variable. Multiple linear regression model includes one dependent and multiple independent variables. In some cases, the number of dependent variables may be more than one, as may be the number of independent variables. In such cases, multivariate multiple regression analysis is used to examine linear relationships between dependent and independent variables. In MRA, the number of dependent variables is important, and must be more than one dependent variable. If dependent and independent variables are continuous variables, multivariate multiple linear regression is used to investigate the linear relationship between the dependent and independent variables (Dattalo, 2013).

In cases where the number of dependent variables is two or more, multivariate multiple linear regression analysis, which is the generalized version of multiple linear regression analysis is used. The calculation of the sum of squares and coefficient estimates required to determine the validity of the model are similar to those of multiple linear regression analysis (Ozdamar, 2004).

The multivariate multiple linear regression model is given by Equation (2):

$$
Y=X \beta+\varepsilon
$$

where Y; nxp dimensional dependent variable matrix, $\mathrm{X} ; \mathrm{nx}(\mathrm{q}+1)$ dimensional independent variables matrix, $\beta$; $(\mathrm{q}+1) \mathrm{xp}$ the matrix of regression coefficients and In cases where the number of dependent variables is two or more, multivariate multiple linear regression $\varepsilon$ shows nxp dimensional error matrix.

In order to perform multivariate multiple regression analysis, some assumptions must be realized. These; the expected value of the error matrix is zero, ie this assumption, expressed as $\mathrm{E}(\mathrm{Y})=\mathrm{XB}$, indicates that the model is linear. The second assumption is error matrix are unrelated. This assumption is related to the covariance matrix. The final assumption is that the error matrix has a multivariate normal distribution (Srivasta and Khatri, 1979).

The Akaike information criterion, AIC, was developed by Akaike (1974) to estimate between the model generating the data and a fitted model. AIC is widely used in model selection and a biased estimator. 
Some features of AIC are listed as follows:

- In model comparisons, the model with the lowest AIC value is always preferred.

- AIC is valid not only within the selected sample size but also in the future forecast

outside the selected sample size.

- It can be used easily in nested, non-nested and interlaced models.

\section{RESULTS}

Table 3 shows 15 experiments produced with control variables ball charge $(B C)$, material charge $(M C)$ and time of grinding $(T M)$ as well as Opacity $(O P)$, Brightness $(B R)$ and average particle size $\left(\mathrm{d}_{50}\right)$.

Table 3. Independent and Dependent Variables (OP, BR and $\left.\mathrm{d}_{50}\right)$

\begin{tabular}{ccccccc}
\hline Experiment & $\begin{array}{c}\mathrm{X} 1 \\
(\mathrm{BC})\end{array}$ & $\begin{array}{c}\mathrm{X} 2 \\
(\mathrm{MC})\end{array}$ & $\begin{array}{c}\mathrm{X} 3 \\
(\mathrm{TM})\end{array}$ & $\begin{array}{c}\mathrm{Y} 1(\mathrm{OP}) \\
(\%)\end{array}$ & $\begin{array}{c}\mathrm{Y} 2(\mathrm{BR}) \\
\left(85^{\circ}\right)\end{array}$ & $\begin{array}{c}\left.\mathrm{Y} 3(\mathrm{~d})_{50}\right) \\
(\mu \mathrm{m})\end{array}$ \\
1 & 0.45 & 0.14 & 30 & 88.73 & 1.4 & 12 \\
2 & 0.4 & 0.14 & 30 & 88.47 & 1.5 & 12 \\
3 & 0.35 & 0.14 & 30 & 89.28 & 1.3 & 14 \\
4 & 0.3 & 0.14 & 30 & 88.26 & 1.3 & 15 \\
5 & 0.25 & 0.14 & 30 & 88.34 & 1.3 & 16 \\
6 & 0.25 & 0.21 & 30 & 83.58 & 1.3 & 15 \\
7 & 0.25 & 0.19 & 30 & 84.71 & 1.4 & 15 \\
8 & 0.25 & 0.16 & 30 & 84.30 & 1.3 & 17 \\
9 & 0.25 & 0.14 & 30 & 85.02 & 1.5 & 19 \\
10 & 0.25 & 0.12 & 30 & 85.79 & 1.5 & 20 \\
11 & 0.25 & 0.19 & 120 & 83.19 & 1.6 & 9 \\
12 & 0.25 & 0.19 & 90 & 81.84 & 1.5 & 11 \\
13 & 0.25 & 0.19 & 60 & 81.73 & 1.6 & 12 \\
14 & 0.25 & 0.19 & 45 & 81.96 & 1.4 & 14 \\
15 & 0.25 & 0.19 & 30 & 83.04 & 1.6 & 17
\end{tabular}

In the next step, multivariate multiple linear regression analysis was applied and the results are presented in Table 4. As seen in Table 4, AIC was found to be 59.6315.

Table 4. Multivariate Multiple Regression Analysis Results

\begin{tabular}{cccc}
\hline & OP & BR & $\mathbf{d}_{50}$ \\
Constant & $82.7383(4.4112)^{* *}$ & $1.2452(0.1739)$ & $13.3053(3.8902)$ \\
BC & $-8,6927(1.8074)$ & $-0.0494(0.0083)$ & $78.4495(15.7321)$ \\
MC & $43.2573(12.9523)$ & $0.4463(0.1482)$ & $-65.6294(38.1924)$ \\
TM & $0.0077(0.0181)$ & $-0.0002(0.0012)$ & $-0.0432(0.0373)$ \\
AIC & & 59.6315 & \\
${ }^{*}$ :Valuesarum in parentheses indicate standard error values.
\end{tabular}

Equation (3), (4), and (5) show the models for OP, BR, and $\mathrm{d}_{50}$.

$$
\begin{aligned}
& O P=82.7383-8.6927 * B C+43.2573 * M C+0.0077 * T M \\
& B R=1.2452-0.0494 * B C+0.4463 * M C-0.0002 * T M \\
& d_{50}=13.3053-78.4495 * B C-65.6294 * M C-0.0432 * T M
\end{aligned}
$$

Then, $d_{50}$ was excluded from the analysis because it was found not significant. In the next step, multivariate multiple linear regression analysis was applied and the results are seen in Table 5. As shown in Table 5, AIC was found to be 17.7874 .

Table 5. Multivariate Multiple Regression Analysis Results without $\mathrm{d}_{50}$

\begin{tabular}{ccc}
\hline & OP & BR \\
Constant & $82.5213(4.0754)^{*}$ & $1.2455(0.1545)$ \\
BC & $-8.8227(1.6502)$ & $-0.0554(0.0075)$ \\
MC & $43.1563(10.7992)$ & $0.3484(0.1164)$ \\
TM & $0.0078(0.0012)$ & $0.0003(0.00012)$ \\
AIC & \multicolumn{2}{c}{17.7874} \\
":Valuesarum in parentheses indicate standard error values.
\end{tabular}

Equations, (6) and (7) show the models for OP and BR.

$$
\begin{aligned}
& O P=82.5213-8.8227 * B C+43.1563 * M C+0.0078 * T M \\
& B R=1.2455-0.0554 * B C+0.3484 * M C-0.0003 * T M
\end{aligned}
$$

When the two models are compared (with $\mathrm{d}_{50}$ and without $\mathrm{d}_{50}$ ), the model with the smaller AIC value is selected. Accordingly, the model (without $\mathrm{d}_{50}$ ) expressed by Eqs. (6) and (7) is better. It was observed that removing the $d_{50}$ variable gives better results because, AIC value is lowest.

One of the assumptions of MRA, whether the error matrix comes from the multivariate normal distribution should be tested. Multivariate Normality tests are using t value and its p value. Accordingly, for Equations (6) and (7), it was tested whether the error matrix came from the multivariate normal distribution. The analysis results are given in Table 6. According to Table 6, it is seen that the error matrix

Table 6. Multivariate Normality Test

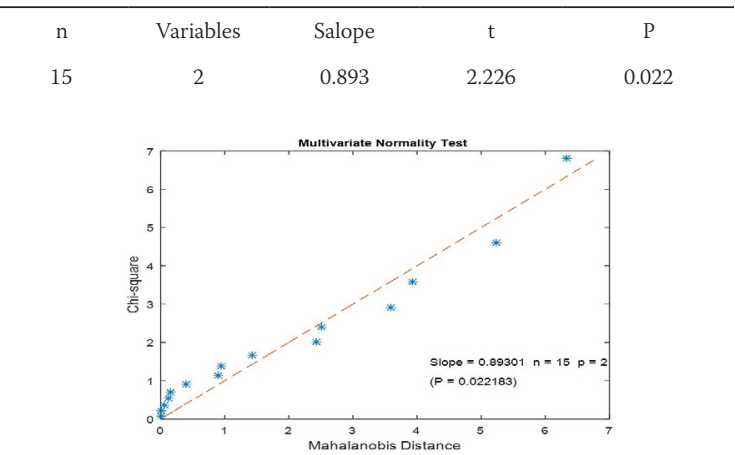

Figure 2. Results for Multivariate Normality Test 
has a multivariate normal distribution at $1 \%$ significance level $(p>0,01)$. The result of the multivariate normality test is shown in Fig. 2. Equations (6) and (7) can be used for interpretation.

Within this research, MRA is found convenient to explain the changes on the water-based paint dry film properties developed by the varying talc product characteristics in the recipe due to different grinding parameters.

\section{DISCUSSION}

In this study, multivariate multiple regression analysis was used for modeling. A model was created through the combined use design of mixtures.

Using the equations of a linear model showed that it was possible to foresee the value of the OP and BR for any change of the grinding parameter used.

While the other variables were constant, when the value of $\mathrm{BC}$ was increased by one unit, the value of OP decreased by 8.8227 units. When the value of $\mathrm{MC}$ was increased by one unit, the value of OP increased by 43.1563 units. Similarly, when the value of $\mathrm{BC}$ was increased by one unit, the value of BR results in a decrease of 0.0554 units. One unit increase in $\mathrm{MC}$ leads to an increase in the value of $\mathrm{BR}$ by 0.3484 units

It can easily be seen from the results obtained from this study that there is a direct relationship between ball charge (BC) and the average particle size $\left(d_{50}\right)$ of talc samples used in paint. With the increase in $\mathrm{BC}$ for the grinding, more effective grinding conditions were supplied and produced smaller particle sizes $\left(d_{50}\right)$ talc samples. However, smaller particle size does not indicate better OP properties in the paint. Oppositely, in our studies, the hiding power/opacity decreased with the decrease of the average particle size $\left(d_{50}\right)$ due to increased $\mathrm{BC}$ in the grinding. On the other hand, with the increase of material charge $(M C)$ in the grinding caused a slight decrease at average particle sizes $\left(d_{50}\right)$ of talc samples. Despite, a slight decrease at $d_{50}$ sizes, a significant increase calculated with the OP of the paint. This can be explained as; when we increase the amount of ball in mill cataract and cascade forces be more effective and get better grinding conditions to result with smaller size but also rounded (with less aspect ratio) particles.

When the amount of material(talc) was increased in the mill, then the effect of cataract and cascade forces were decreased, and results with bigger sized (compared to high $\mathrm{BC}$ grindings) but less rounded (with higher aspect ratio) particles. Talc particles would probably have larger platy surfaces due to higher $\mathrm{d}_{50}$ size, less rounded shape and higher aspect ratio, and will improve the hiding power/opacity of the paint. With the increase of material charge $(\mathrm{MC})$ in grinding caused a significant increase at OP of the paint.

It can be said from the XRD analysis of raw and gro-

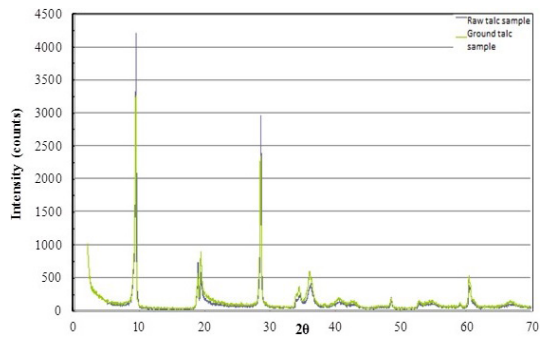

Figure 3. Mineralogical Analysis (XRD) of raw and ground talc samples.

und talc samples given in Fig. 3. that there was no significant change in the crystal/cage structure of talc after grinding. Addition to this, the corners of the structure were rounded after the grinding.

It can clearly be seen from the particle size (2) dimension calculations on SEM photos by using the auto-cad program before and after the grinding that the aver. the aspect ratio was significantly changed/decreased due to grinding as shown in Table 7.

Table 7. Measured dimensions and aspect ratios of talc samples

\begin{tabular}{ccccccccc}
\hline $\begin{array}{c}\text { Particle } \\
\text { no }\end{array}$ & \multicolumn{3}{c}{ Raw Talc Samples } & \multicolumn{4}{c}{ Ball Mill Talc Samples } \\
1 & L.E & S.E. & A.R. & C.R. & L.E. & S.E. & A.R. & L.E. \\
1 & 15.56 & 8.19 & 1.90 & 0.720 & 11.1 & 9.17 & 1.21 & 0.710 \\
2 & 11.03 & 6.80 & 1.62 & 0.660 & 22.00 & 12.18 & 1.81 & 0.794 \\
3 & 29.76 & 19.39 & 1.53 & 0.619 & 7.81 & 4.91 & 1.59 & 0.614 \\
4 & 12.25 & 5.38 & 2.28 & 0.683 & 14.33 & 9.73 & 1.47 & 0.796 \\
5 & 30.53 & 11.03 & 2.77 & 0.566 & 12.17 & 9.76 & 1.25 & 0.571 \\
6 & 10.42 & 7.00 & 1.49 & 0.542 & 11.10 & 9.17 & 1.21 & 0.802 \\
7 & 12.37 & 6.21 & 1.99 & 0.639 & 9.94 & 5.11 & 1.95 & 0.534 \\
8 & 10.22 & 5.52 & 1.85 & 0.694 & 10.00 & 4.84 & 2.07 & 0.698 \\
9 & 16.64 & 15.89 & 1.05 & 0.583 & 10.30 & 5.88 & 1.75 & 0.703 \\
10 & 12.76 & 5.09 & 2.51 & 0.608 & 10.92 & 9.93 & 1.10 & 0.527 \\
11 & 24.11 & 11.55 & 2.09 & 0.626 & 14.33 & 9.73 & 1.47 & 0.576 \\
12 & 13.09 & 5.58 & 2.35 & 0.725 & 7.81 & 4.91 & 1.59 & 0.590 \\
13 & 10.07 & 5.52 & 1.82 & 0.735 & 8.65 & 5.23 & 1.65 & 0.644 \\
14 & 8.89 & 5.79 & 1.54 & 0.671 & 7.92 & 4.84 & 1.64 & 0.836 \\
15 & 14.99 & 9.82 & 1.53 & 0.659 & 14.85 & 6.99 & 2.12 & 0.713 \\
16 & 13.04 & 7.02 & 1.86 & 0.652 & 7.67 & 5.03 & 1.52 & 0.514 \\
17 & 9.06 & 8.33 & 1.09 & 0.541 & 12.51 & 6.34 & 1.97 & 0.701 \\
Aver. & $\mathbf{1 4 . 9 8}$ & $\mathbf{8 . 4 7}$ & $\mathbf{1 . 7 7}$ & $\mathbf{0 . 6 4 2}$ & $\mathbf{1 1 . 3 7}$ & 7.28 & $\mathbf{1 . 5 6}$ & $\mathbf{0 . 6 6 6}$
\end{tabular}

L.E. : Long edge

S.E. : Short edge

A.R. : Aspect ratio

C.R. : Circularity

The circularity of talc particles was also calculated on the 2D image given in Fig. 4. After the calculation, it was seen in Table 7 that the particles become more circular/ro- 


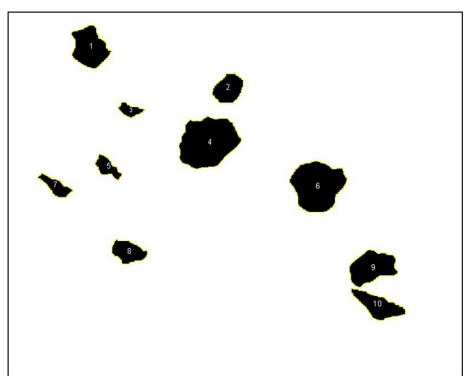

Figure 4. 2D image of ground talc particles.

unded after grinding.

The increase of $B C$ and $M C$ had a very minor effect on $B R$ of paint, therefore, can be ignored.

\section{CONCLUSION}

In this study talc mineral was ground at different grinding conditions and utilized as the variable mineral filler of a water-based paint recipe. Multivariate multiple regression analysis was applied to foresee the influence of grinding parameters of talc to the properties of the paint.

The results showed that it was possible to foresee the changes on OP and BR of a dry film depends on the mineral filler characteristics in the same paint. In other words, it was possible to foresee the changes on $\mathrm{OP}$ and $\mathrm{BR}$ of the paint due to changing grinding parameters of talc used as mineral filler in paint by using MRA. Besides that, applying this regression analysis, the main effects of each parameter of the grinding can be determined to paint basic properties.

\section{ACKNOWLEDGEMENT}

The authors would like to thank the Research Fund Unit of Afyon Kocatepe University for financial support (AKU 17.FEN.BİL.63).

\section{REFERENCES}

1. Akaike, H, 1974, A new look at the statistical model identification, IEEE Transaction on Automatic Control 19, 716-723.

2. Bezerra, M.A., Santelli, R.E., Oliveira, E.P., Villar, L.S., Escaleira, L.A.,2008, Response surface methodology (RSM) as a tool for optimization in analytical chemistry, Talanta 76, 965-977.

3. Box, G. E., Hunter, J. S., 1961, The $2 \mathrm{k}-\mathrm{p}$ fractional factorial designs. Technometrics, 3, 311- 351 .

4. Ciullo P.A., 1996, Industrial Minerals and Their Uses, A Handbook \& Formulary, Noyes Publication, Westwood New Jersey, 125-136.

5. Conceição, Petter \& Sampaio, 2018, Prediction of water-based paint properties based on their mineral fillers; Simplex-PLSR coupling application, 3-5.

6. Dattalo, P, 2013, Analysis of Multiple Dependent Variables. Oxford University, Oxford.

7. DPT, (2001), Particular Industrial Minerals, Sub-commission Soil-based Industrial Raw Materials I. Special Commission Report, Ankara.

8. Grim, R., 1968, Clay mineralogy, McGraw-Hill Book Company, New York, 596.

9. Gündüz, G., 2005, Paint information. TMMOB Chamber of Chemical Engineers, p.461.

10. Karakaş, F., 2011, Functioning Mechanism of Industrial Minerals in Water-based Paints, Ph.D. Thesis Istanbul Technical University, Institute of Science, Mining Engineering Dept., p.185, Istanbul Turkey.

11. Menezes, R. R., Malzac Neto H. G., Santana, L. N. L., Lira, H. L., Ferreira, H. S. and Neves, G. A., 2008, Optimization of wastes content in ceramic tiles using statistical design of mixture experiments, Journal of the European Ceramic Society, 28, 30273039.

12. Özdamar, K, 2004, Statistical Data Analysis with Package Programs, Kaan Publishes, Eskisehir Turkey.

13. Paksoy S., 1999, Paint Handbook, TMMOB Chamber of Chemical Engineers, Istanbul.

14. Srivastava, M., Khatri, C, 1979, An Introduction to Multivariate Statistics. North Holland, New York, USA.

15. Wold, H.,1973, "Nonlinear Iterative Partial Least Squares (NIPALS) modelling: Some current developments.” In Multivariate Analysis III. Proceedings of the 3rd International Symposium on Multivariate Analysis. Dayton, Ohio, edited by P. R. Krishnaiah, 383-407. Academic Press.

16. Wold, S., Sjöström, M., Eriksson, L., 2001, Chemometrics and Intelligent Laboratory Systems 58, 109-130.

17. Yekeler, M., Ulusoy, U., Hiçyılmaz, C., 2004, Effect of particle shape and roughness of talc mineral ground by different mills on the wettability and floatability, Powder Technology, 140, 68-78.

18. Yürekli, Ş., 1997, Resine and Paint Technology, Istanbul 